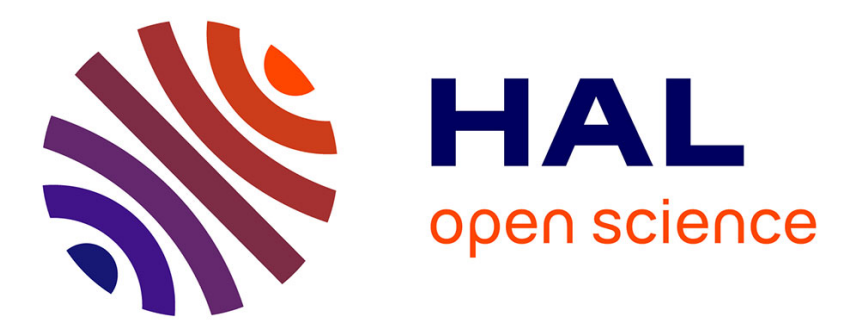

\title{
Histological Analysis of Tibialis Anterior Muscle of DMDmdx4Cv Mice from 1 to 24 Months
}

Sabrina Ben Larbi, Marielle Saclier, Aurélie Fessard, Gaëtan Juban, Bénédicte Chazaud

\section{- To cite this version:}

Sabrina Ben Larbi, Marielle Saclier, Aurélie Fessard, Gaëtan Juban, Bénédicte Chazaud. Histological Analysis of Tibialis Anterior Muscle of DMDmdx4Cv Mice from 1 to 24 Months. Journal of Neuromuscular Diseases, 2021, 8 (4), pp.513-524. 10.3233/JND-200562 . inserm-03404655

\section{HAL Id: inserm-03404655 https://www.hal.inserm.fr/inserm-03404655}

Submitted on 26 Oct 2021

HAL is a multi-disciplinary open access archive for the deposit and dissemination of scientific research documents, whether they are published or not. The documents may come from teaching and research institutions in France or abroad, or from public or private research centers.
L'archive ouverte pluridisciplinaire HAL, est destinée au dépôt et à la diffusion de documents scientifiques de niveau recherche, publiés ou non, émanant des établissements d'enseignement et de recherche français ou étrangers, des laboratoires publics ou privés. 
3 Sabrina Ben Larbi ${ }^{1}$, Marielle Saclier ${ }^{2}$, Aurélie Fessard ${ }^{1}$, Gaëtan Juban $^{1}$, Bénédicte Chazaud ${ }^{1}$

5 1- Institut NeuroMyoGène, Université Claude Bernard Lyon 1, CNRS UMR 5310, INSERM

6 U1217, Université Lyon, Villeurbanne 69100, France

7 2- Department of Biosciences, University of Milan, 20133 Milan, Italy

8

9

10

11 Running title: Histology of $D M D^{m d \times 4 c v}$ mice muscle

12

13 Corresponding author

14 Bénédicte Chazaud

15 Institut NeuroMyoGène, Faculté de Médecine, 8 Avenue Rockefeller, F-69008 Lyon

16 Tel: (33) 426688249

17 benedicte.chazaud@inserm.fr 


\section{ABSTRACT}

BACKGROUND: The $m d x-C 57 / B 6$ mouse model does not show the clinical signs of Duchenne muscular dystrophy (DMD), although muscles exhibit hallmarks of permanent regeneration and alterations in muscle function. The $\mathrm{DMD}^{m d \times 4 C v}$ strain exhibits very few revertant dystrophin positive myofibers, making that model suitable for studies on gene and cell therapies.

OBJECTIVE: The study appraises the histological evolution of the Tibialis Anterior muscle of WT and $D M D^{m d \times 4 C v}$ mutant from 1 to 24 months.

METHODS: Histological analysis included a series of immunostainings of muscle sections for assessing tissue features (fibrosis, lipid deposition, necrosis) and cellular characteristics (size of myofibers, number and distribution of myonuclei, number of satellite cells, vessels, macrophages).

RESULTS: None of the investigated cell types (satellite cells, endothelial cells, macrophages) showed variations in their density within the tissue in both WT and $D M D^{m d x 4 C v}$ muscle. However, analyzing their number per myofiber showed that in $D M D^{m d \times 4 C v}$, myofiber capillarization was increased from 1 to 6 months as compared with WT muscle, then dropped from 12 months. Macrophage number did not vary in WT muscle and peaked at 6 months in $D M D^{m d \times 4 C v}$ muscle. The number of satellite cells per myofiber did not vary in WT muscle while it remained high in $D M D^{m d x 4 C v}$ muscle, starting to decrease from 12 months and being significantly lower at 24 months of age. Myofiber size was not different in $D M D^{m d \times 4 C v}$ from WT except at 24 months, when it strongly decreased in $D M D^{m d \times 4 c v}$ muscle. Necrosis and lipid deposition were rare in $D M D^{m d \times 4 C v}$ muscle. Fibrosis did not increase with age in $D M D^{m d \times 4 C v}$ muscle and was higher than in WT at 6 and 12 months of age.

CONCLUSION: As a whole, the results show a strong decrease of the myofiber size at 24 months, and an increased capillarization until 6 months of age in $D M D^{m d x 4 C v}$ as compared with the WT. Thus, $D M D^{m d \times 4 C v}$ mice poorly recapitulates histological DMD features, and its use should take into account the age of the animals according to the purpose of the investigation.

Keywords: $m d x$ - aging - histology - Duchenne muscular dystrophy 


\section{INTRODUCTION}

Duchenne muscular dystrophy (DMD) is a progressive X-linked neuromuscular disorder due to mutations in the $D M D$ gene, that encodes for dystrophin. Dystrophin belongs to a large transmembrane complex (dystrophin associated glycoprotein complex) that links the intracellular cytoskeleton of the myofiber to the extracellular matrix. The absence of dystrophin leads to recurrent myofiber damages (1), that trigger the activation of satellite cells, or muscle stem cell (MuSC)s and their entry into the myogenesis program, in attempt to repair the damaged myofibers (2). Although highly efficient in normal skeletal muscle, the process of regeneration eventually fails in DMD due to chronic myofiber damage (1), leading to the replacement of the muscle parenchyma by fibrosis and lipid deposition. Moreover, a pro-fibrotic environment is associated with a deficit in myogenesis (3). The most used model for DMD is the $m d x$ mouse, which bears a nonsense mutation in the Dmd gene (4). On the contrary to human, $m d x$ mice do not show clinical signs of the disease, move and live normally. However, $m d x$ mice are easy to breed and the $m d x$ hindlimb muscle shows signs of permanent regeneration associated with alterations in muscle function when specifically stimulated (5-7). Therefore, despite its limitations, the $m d x$ mouse is widely used as a model for understanding the physiopathological mechanisms sustaining DMD and as a preclinical model to test therapeutic strategies.

Most of the longitudinal studies describing $m d x$ skeletal muscle tissue all life long were mainly done with C57/BL10 mice, the original background of the $m d x$ mouse (here after referred as B10-mdx) (8-11). More recent studies have been using a C57/B6 background, and the $D M D^{m d \times 4 C v}$ and $D M D^{m d \times 5 C v}$ mutants because they show a low frequency of reversion mutations (12).

A crucial parameter to consider when evaluating $m d x$ muscle phenotype or function is the age of the animal. Of most importance, B10-mdx mice show an episode of acute myofiber degeneration at 3-4 weeks of age (at time of weaning) that leads to an important process of regeneration (13-15). Thereafter, continuous cycles of damage and regeneration lead to more than $80-90 \%$ of myofibers exhibiting hallmarks of regeneration at 3 months of age $(15,16)$. 
Second, from several pioneers studies that investigated B10- $m d x$ muscle at various ages (from 10 to 24 months), it was admitted that time accelerates the dystrophic process, although high variations were observed between the studies $(8,9,17-19)$. As a result, the literature in the field encompasses studies using a variety of time ranges using the $m d x$ model, animals being considered as "old" from 10 to 22 months.

One of the most commonly used readouts of muscle homeostasis are histological parameters, such as the number and size of myofibers, the number of satellite cells, of vessels, etc. Having established a series of samples that were used for previous studies, we took the opportunity to perform a histological comparative analysis of these samples, which were Tibialis Anterior (TA) muscle of the C57/B6 $D M D^{m d x 4 C v}$ mouse strain, from 1 to 24 months of age. TA muscle is one of the mostly used for investigation of MuSC biology. The B6 background is also very popular because of the use of many transgenic strains for the study of muscle biology. In the $\mathrm{DMD}^{m d \times 4 \mathrm{Cv}}$ model, a $\mathrm{C}$ to $\mathrm{T}$ transition in exon 53 at position 7916 creates a premature ochre stop codon (CAA to TAA) (20). DMD ${ }^{m d x 4 C v}$ mouse strain exhibits low frequency of reversion mutations, rendering that model suitable for gene and cell therapy in preclinical investigations (12). 


\section{MATERIALS AND METHODS}

Mice experiments and histology. WT and $D M D^{m d x 4 C v}(20)$ on C57BL/6J background males from 1 to 24 months of age were used according to the French legislation (Approval from local Animal Care and Use Committee was obtained under ref CEE A34.BC-RM.053.12). 5 mice were used at each time point. The TA muscle was recovered and was frozen in liquid nitrogenprecooled isopentane, and stored at $-80^{\circ} \mathrm{C}$ until use. Ten micrometer-thick cryosections were made and used for stainings and immunostainings.

Histological stainings. Hematoxylin-eosin (HE) was used for morphological observation of the muscle tissue. To label lipids, sections were stained with Sudan Black solution (199664, Sigma) for $2 \mathrm{~h}$ and were counterstained with Hemalun (MHS80, Sigma) for $1 \mathrm{~min}$. Whole muscle sections were reconstituted with Image J software after recording at x10 objective using a Zeiss axioskop microscope and an Axiocam ICC5 zeiss camera. The area of black staining (Sudan black staining) was measured using ImageJ software using the AutoThreshold Yen and Analyze/histogram function.

Immunolabeling for satellite cells. Muscle sections were fixed with paraformaldehyde (4\%) for $10 \mathrm{~min}$ at room temperature and permeabilized with Triton X-100 (0.5\%) before acidic antigen retrieval was performed (Citrate buffer $10 \mathrm{mM}$ at $90^{\circ} \mathrm{C}$ for $5 \mathrm{~min}$ ). Slides were incubated with primary antibodies against Pax7 (1/50, Developmental Studies Hybridoma Bank, DSHB) overnight at $4^{\circ} \mathrm{C}$, then washed with PBS and further incubated with FITC-conjugated secondary antibodies (1/200, Jackson ImmunoResearch Laboratories). A biotin-conjugated secondary antibody (1/200 Vector laboratory, BA-2000) revealed by a DTAF-conjugated streptavidin (1/1000, Beckman Coulter, PN IM0307) was used to amplify the signal as previously described (21). Muscle sections were then incubated with anti-laminin antibodies $\left(1 / 100\right.$, L9393 sigma) that stains all basal membranes, for $2 \mathrm{~h}$ at $37^{\circ} \mathrm{C}$, washed and further incubated with Cy3-conjugated secondary antibodies (1/200, Jackson ImmunoResearch Laboratories) for $45 \mathrm{~min}$ at $37^{\circ} \mathrm{C}$. Sections were washed with PBS, incubated in Hoechst solution for $10 \mathrm{sec}$, and then mounted with Fluoromount (FP483331, Interchim). About 12 pictures covering all areas of the muscle section were taken at $x 20$ objective using Zeiss Z1 
imager microscope and a Photometrics CoolSnap camera. The number of muscle stem cells $\left(P a x 7^{\text {pos }}\right)$ was manually counted using ImageJ software as well as the number of myofibers (thanks to laminin immunostaining). Results are given in number of cells/myofiber or in number of cells $/ \mathrm{mm}^{2}$ of muscle section.

Immunolabeling for macrophages. Muscle sections were directly incubated with primary antibodies against F4/80 (1/200 ab6640 Abcam) overnight at $4^{\circ} \mathrm{C}$, then washed with PBS and further incubated with Cy3-conjugated secondary antibodies (1/200 Jackson ImmunoResearch Laboratories). Muscle sections were then fixed with paraformaldehyde (4\%) for $10 \mathrm{~min}$ at room temperature and permeabilized with Triton $\mathrm{X}-100$ (0.5\%) before immunolabeling for laminin as described above for satellite cells. About 12 pictures covering all areas of the muscle section were taken at x20 objective using Zeiss Z1 imager microscope and a Photometrics CoolSnap camera. The number of macrophages $\left(\mathrm{F} 4 / 80^{\mathrm{pos}}\right)$ was manually counted using ImageJ software as well as the number of myofibers (thanks to laminin immunostaining). Results are given in number of cells/myofiber or in number of cells $/ \mathrm{mm}^{2}$ of muscle section.

Immunolabeling for endothelial cells. Muscle sections were fixed with paraformaldehyde (4\%) for $10 \mathrm{~min}$ at room temperature and permeabilized with Triton X-100 (0.5\%) before incubation with primary antibodies against $\operatorname{CD} 31\left(1 / 200\right.$, ab7388, Abcam) overnight at $4^{\circ} \mathrm{C}$, then washed with PBS and further incubated with Cy3-conjugated secondary antibodies (1/200, Jackson ImmunoResearch Laboratories). Muscle sections were then treated for the detection of laminin as described above for satellite cells. About 12 pictures covering all areas of the muscle section were taken at $\mathrm{x} 20$ objective using Zeiss Z1 imager microscope and a Photometrics CoolSnap camera. The number of capillaries $\left(\mathrm{CD} 31^{\text {pos }}\right)$ was manually counted using Image J software as well as the number of myofibers (thanks to laminin immunostaining). Results are given in number of cells/myofiber or in number of cells $/ \mathrm{mm}^{2}$ of muscle section.

Immunolabeling for collagen 1. Muscle sections were fixed with paraformaldehyde (4\%) for 10 min at room temperature and permeabilized with Triton X-100 (0.5\%) before incubation with primary antibodies against collagen 1 (1310-01, Southern Biotech) overnight at $4^{\circ} \mathrm{C}$, then 
washed with PBS and further incubated with Cy3-conjugated secondary antibodies (1/200, Jackson ImmunoResearch Laboratories) and mounted with Fluoromount (FP483331, Interchim). About 12 pictures covering all areas of the muscle section were taken at $\times 20$ objective using Zeiss Z1 imager microscope and a Photometrics CoolSnap camera. Fibrosis was quantified after collagen I immunolabelling as in (22). Whole muscle sections were automatically scanned at $\times 10$ of magnification using an Axio Observer.Z1 (Zeiss) connected to a CoolSNAP HQ2 CCD Camera (photometrics).

Immunolabeling for damaged myofibers. Muscle sections were fixed with paraformaldehyde (4\%) for $10 \mathrm{~min}$ at room temperature and permeabilized with Triton X-100 $(0.5 \%)$ before incubation with donkey anti-mouse FITC-conjugated IgGs (Jackson ImmunoResearch Laboratories) overnight at $4^{\circ} \mathrm{C}$, then washed with PBS and mounted with Fluoromount (FP483331, Interchim). Whole muscle sections were automatically scanned at $\times$ 10 of magnification using an Axio Observer.Z1 (Zeiss) connected to a CoolSNAP HQ2 CCD Camera (photometrics). The area of IgG positive myofibers was manually delineated. Results are given in $\%$ of the total muscle section area.

Analysis of myofiber CSA. Whole muscle sections were automatically scanned at $\times 10$ of magnification using an Axio Observer.Z1 (Zeiss) connected to a CooISNAP HQ2 CCD Camera (photometrics). Myofiber cross-section area (CSA) was calculated on whole muscle sections using Open-CSAM software based on laminin staining as previously described (23).

Analysis of myonuclei. 12 pictures covering all areas of the muscle section immunolabelled for laminin were taken at $\mathrm{x} 20$ objective using Zeiss Z1 imager microscope and a Photometrics CoolSnap camera. The number of myonuclei per myofiber (distinguishing the myofibers with peripheral versus central nuclei) was manually counted using ImageJ software.

Statistics. For each time point, 5 mice were analyzed in a non-blinded way by two independent experimenters. Statistical analyses included One-way Anova after checking normality or ManWhitney test for non-parametric data. $\mathrm{P}<0.05$ was considered significant. 


\section{RESULTS AND DISCUSSION}

TA muscles from WT and $\mathrm{DMD}^{m d \times 4 \mathrm{Cv}}$ from 1 to 24 months were proceeded for histological stainings and immunostainings. While $\mathrm{DMD}^{m d \times 4 \mathrm{Cv}}$ muscle showed several signs of necrosis, inflammation, heterogeneity in fiber size and signs of regeneration as compared with WT, there was no obvious macroscopic changes in the muscles with age (HE staining examples are given in Figure Suppl1).

\section{Myofibers.}

Laminin immunolabeling (Figure 1A) was used to analyze various parameters of myofibers. After the huge regeneration process observed at 3 weeks, the number of regenerating myofibers increases in $m d x$ muscles, reaching about $80 \%$ after a few weeks and remaining high until 2 years of age $(19,24)$. We evaluated the number of myonuclei/myofiber in both nonregenerating myofibers (that present a peripheral location of their nuclei) and regenerating/regenerated myofibers (exhibiting myonuclei in a central location) in about 12 pictures taken randomly in the whole section. In WT muscle, myonuclei were mainly present at the periphery of myofibers (Figure 1B). Rare myonuclei were present in a central position, reflecting isolated fusion events all life long, with no increase with age (Figure 1B). In $\mathrm{DMD}^{m d \times 4 \mathrm{Cv}}$ muscles, the number of myonuclei dramatically increased in myofibers with central myonuclei from 3 months of age (+272\% vs 1 month), likely reflecting the transition from an acute to a chronic regenerating state of the muscle (Figure 1B). Concomitantly, the number of nuclei in myofibers exhibiting only peripheral nuclei declined (Figure 1B). It was previously reported that myofibers isolated from Soleus, Extensor Digitorum Longus and Flexor Digitorum Brevis (FDB) muscles show abnormalities from 4 months of age, which increase after 6 months to reach $90 \%$ of myofibers (30\% in FDB) (25). Adding a level of complexity in the analysis of $m d x$ muscle using transversal sections, both peripheral and central nuclei were observed along the same myofiber in B10-mdx muscle $(11,25)$.

Next, the number and size of myofibers were evaluated on entire muscle sections. In both WT and $\mathrm{DMD}^{m d \times 4 \mathrm{Cv}}$ muscles, the number of myofibers per unit area decreased from 1 to 3 months. Then, it did not vary in WT while in $\mathrm{DMD}^{m d \times 4 \mathrm{Cv}}$ muscle, the number of myofibers increased at 
24 months (Figure 1C). Similarly, a previous study indicated no high variation between 3 and 12 months of age in B10-mdx hindlimb muscles (17).

Myofiber size is a popular feature to assess skeletal muscle regeneration. We used a semiautomated tool to measure myofiber CSA in regenerating conditions on entire muscle sections (23). Results of the mean CSA (Figure 1D) and CSA distribution (Figure 1E,F) showed that in both WT and DMD ${ }^{m d x 4 C v}$ muscles, CSA increased at 3 months (+157 and $182 \%$ vs 1 month, respectively). Thereafter, the mean myofiber CSA did not vary until a very late time point, i.e. at 24 months (-59\% vs 12 months), where the smallest CSA was observed in $\mathrm{DMD}^{m d \times 4 \mathrm{Cv}}$ muscles, in accordance with the increased number of myofibers at this last time-point (Figure 1C). This decrease was not observed in WT muscles, although the distribution of myofiber CSA showed an increased number of smaller myofibers at 24 months (Figure 1E). In $\mathrm{DMD}^{m d \times 4 \mathrm{Cv}}$ muscles, the distribution of myofiber CSA varied according to the CSA mean, with the smallest myofibers being observed at 1 and 24 months, while bigger myofibers were observed in 6-month-old animals (Figure 1F). Previous studies reported myofiber hypertrophy during the first months of life of B10-mdx, likely in response to the huge degenerating process occurring at $3-5$ weeks of age $(5,17,26)$. Another study showed an increase of the myofiber CSA at 12 months (17). However, other analyses indicated that at 10 months of age, B10-mdx muscles exhibit an increase of both small and large myofibers $(11,27)$. It is likely that this great heterogeneity is due to myofiber branching, which has been repeatedly reported $(7,25)$ to increase with age (28) and to be very important after 2 years $(11,29)$. Myofiber branching is associated with an alteration of calcium signaling and of excitation/contraction coupling, leading to defects in myofiber function $(30,31)$. Myofiber branching is observed in aged normal skeletal muscle, with about $15 \%$ of myofibers exhibiting 2 branches (32). In contrast, myofiber branching is a frequent event in B10-mdx muscle, since $100 \%$ of myofibers of EDL muscle are branched at 17 months of age (33), and this may explain the small myofiber CSA that we observed at 24 months.

\section{Muscle Stem Cells.}


MuSCs have been particularly investigated in the dystrophic context. We performed Pax7

232

immunolabeling to count total (both quiescent and activated) MuSCs in WT and DMD ${ }^{m d \times 4 C v}$ muscles (Figure 2A). When counting the number of MuSCs per area unit, no variation was observed from 1 to 24 months of age in both strains, although the number of MuSCs was always much higher in $\mathrm{DMD}^{m d \times 4 C v}$ than in WT muscle (Figure 2B, Figure Suppl2A,B). When counting the number of MuSCs per myofiber, the only significant difference was observed at 24-month-old in $\mathrm{DMD}^{m d \times 4 C v}$ muscles $(-41 \%)$ (Figure 2C, Figure Suppl2A,B), when muscles exhibited the most myofibers. These results suggest that the number of MuSCs did not vary with age in TA DMD ${ }^{m d x 4 C v}$ muscle. Studies using the same $M y f 5^{\text {nlacz }}$ lineage tracing model and similar isolated EDL single fiber technique reported opposite results with either an increase (33) or a decrease of the number of satellite cells with age (34). Thus, the evolution of the number of MuSCs in $m d x$ strains should be carefully monitored depending on the technique used, genetic background and sex of the animal.

\section{Endothelial cells.}

Skeletal muscle is highly vascularized. Moreover, endothelial cells exert specific effects on MuSC differentiation and myogenesis (35). Immunolabeling for CD31 (PECAM1) allowed to evaluate the number of blood vessels and capillaries (Figure $3 \mathrm{~A}$ ). The number of vessels per surface unit was not significantly altered from 2 to 24 months (Figure 3B). However, when reporting the number of capillaries per myofiber, there was an increase until 6 months in myofiber capillarization in $\mathrm{DMD}^{m d x 4 \mathrm{C} v}$ muscles, as compared with WT, followed by an important drop between 6 and 12 months of age in $D^{2} D^{m d \times 4 C v}$ animals (-47\%) while no variation was observed in WT muscle (Figure 3C and Figure Suppl2C,D). These results are consistent with previous studies showing a reduced number of vessels irrigating each myofiber, anatomical alterations with anastomosis, that is associated with a defect in perfusion in one-year-old $\mathrm{DMD}^{m d \times 4 \mathrm{Cv}}(36)$ and with a low number of capillaries per myofiber at 24 months (26). No specific explanation is available to explain the capillarization drop from 12 months.

\section{Macrophages.}


Macrophages have been shown to be present in dystrophic B10-mdx muscle from early stages (5 weeks) to advanced age $(12$ months) $(5,37)$. A chronic inflammatory response signature was detected in 8-week-old B10-mdx muscle using microarrays (38). Macrophages are important cells during muscle regeneration but were shown to play both beneficial and adverse roles in $m d x$ muscle of various backgrounds $(22,39,40)$. Immunolabeling for the panmacrophage marker F4/80 (Figure 3D) showed that the number of macrophages per unit area was not altered from 2 to 24 months of age in both strains (Figure 3E). However, the number of macrophages was much higher in $\mathrm{DMD}^{m d \times 4 C v}$ muscles than in WT muscles, all life long (from 41 to 91 fold) (Figure E,F). When counting the number of macrophages per myofiber, no change was observed in WT muscle (Figure $3 F$ ). In $\mathrm{DMD}^{m d \times 4 C v}$ muscles, an increase was observed at 6 months where macrophages were at least $x 1.35$ fold more numerous than at any other time point (Figure 3F, Figure Suppl2E,F). Apart this time point, the number of macrophages remained constant, notably at advanced age, indicating that the number of macrophages did not increase with age.

\section{Necrosis.}

In DMD, myofibers undergo chronic cycles of damage/degeneration and regeneration. Muscle sections were labelled with anti-mouse IgGs allows to detect leaky myofibers that uptake serum proteins (41). It was shown that myofibers that appear necrotic in HE staining are positive for plasma protein labelling or for Evans blue dye, although some positively labelled myofibers may appear intact in HE staining $(42,43)$. Only a few reports quantified myonecrosis in $m d x$ muscle. While important necrosis is observed at 3 weeks, its extent is dramatically reduced few days later (44). Figure 4 shows that the number of myofibers labeled with antimouse lgGs was very low, never reaching more that $0.25 \%$ of the total WT muscle area (Figure $4 A, B)$. In $D M D^{m d x 4 C v}$ muscles, the number of positive myofibers was higher but still did not represent more than $1 \%$ of the area of the whole muscle section (Figure $4 A, B$ ). Similarly, Pastoret et al. previously showed that only very few degenerating myofibers are present in B10-mdx muscles from 1 to 24 months (19).

\section{Lipid deposition.}


Lipid deposition due to adipocyte infiltration is, with fibrosis, a hallmark of muscle degeneration in DMD muscle, where the parenchyma, i.e., the myofibers, is replaced by fatty-fibrotic tissue, leading to muscle weakness. Sudan Black stains lipid deposits (Figure 4C). Overall, the extent of lipid deposition in WT and DMD ${ }^{m d \times 4 c v}$ muscles was extremely low, accounting for no more than $0.35 \%$ of the whole muscle section area (Figure 4D). An increase of lipid deposits was observed in $\mathrm{DMD}^{m d \times 4 \mathrm{Cv}}$ muscles at 24 months as compared with the other time points and WT (Figure 4D and Figure Suppl3A). As previously shown in the B10 background, no lipid deposition is present in the $m d x$ muscle at any age, making an important difference with human DMD muscle $(5,18,45)$.

\section{Fibrosis.}

Fibrosis is a major adverse process in DMD since excess of collagen deposit hampers muscle function. It was shown that at the time of diagnosis, endomysial fibrosis is a bad prognosis of motor outcome in DMD patients years later (46). However, B10-mdx hindlimb muscles present no or little fibrosis, contrary to the diaphragm $(47,48)$. While some studies reported no fibrosis in hindlimb muscle until 9-11 months of age $(13,45)$, others mentioned an increase of fibrosis at 23 months but it was not quantified (18). Evaluation of the area of collagen deposition in the TA muscle (Figure 4E and Figure Suppl3B) showed that in $\mathrm{DMD}^{m d \times 4 \mathrm{Cv}}$ muscles, the amount of "fibrosis" accounted for about 14 to $18 \%$ of the muscle field area, and remained stable from 1 month to 24 months of age (Figure 4F), with no evidence of increased fibrosis with age in the whole muscle section (Figure Suppl3). The amount of fibrosis was higher in $\mathrm{DMD}^{m d \times 4 \mathrm{Cv}}$ than in WT muscles at 6 and 12 months of age, but was not significantly different in 24-month-old animals, since collagen area also increased in WT muscle at that time point $(+184 \%$ vs 12 months) (Figure 4F).

\section{CONCLUSION}

Altogether, these results show that the histology of the TA muscle of $D M D^{m d \times 4 C v}$ mice on C57/BL6 background showed modest variations in absolute numbers of the various muscle cell types with age. Myofiber CSA increased at 3 months to remain stable until 24 months 
when it was strongly reduced. None of the cell types evaluated in this study showed a variation in their density within the muscle tissue. However, analyzing their number relative to the number of myofibers indicated that the number of MuSCs decreased at 24 months, that myofiber capillarization was high until 6 months before dropping at later ages. Necrosis and lipid deposition were very rare in the $\mathrm{DMD}^{m d \times 4 \mathrm{Cv}}$ muscle tissue, even at late time points. Finally, collagen I deposition did not increase with age. Overall, the main variations were observed at 24 months of age, when the number of myofibers was strongly increased, probably due to increased branching, inducing a mathematical decrease of all cellular parameters. These results are in accordance with the $\mathrm{DMD}^{m d \times 4 C v}$ mice behavior that move, behave and breed as well as normal mice when maintained in normal conditions. These results also indicate that the use of the $m d x$ model has limitations in mimicking DMD since there is no obvious worsening of the muscle histology with time. This should be taken into account depending on the type of biological investigations and the purpose of the study. Studies aiming at investigating degenerative myopathies in general may prefer other models, such as sarcoglycan deficient mice, that show a natural evolution of the pathology (49), or, for DMD pathology the more recently described DBA/2- $m d x$, where stronger features of degenerative myopathies are observed $(50,51)$. In this model, a link between TGF- $\beta$ pathway, fibrotic areas and myogenesis deficit was evidenced in muscles from young adults (3) while some pathological features appear less severe in older animals $(50,52)$, suggesting that in the DBA/2 model also, the age of the animals should be considered depending on the purpose of the study. 


\section{ACKNOWLEDGMENTS}

337 This work used samples that were established for previous studies that were funded by grants

338 from the Framework Programme FP7 Endostem (under grant agreement 241440), AFM-

339 Telethon (grant 16029 and MyoNeurAlp Alliance), Fondation pour la Recherche Médicale 340 (Equipe FRM DEQ20140329495).

341

$342 \quad$ Conflict of Interest

343 The authors have no conflict of interest to report.

344

345 


\section{REFERENCES}

347 1. Petrof BJ, Shrager JB, Stedman HH, Kelly AM, Sweeney HL. Dystrophin protects the sarcolemma from stresses developed during muscle contraction. Proc Natl Acad Sci USA. 1993;90:3710-4.

2. Yin H, Price F, Rudnicki MA. Satellite cells and the muscle stem cell niche. Physiol Rev. 2013;93:23-67.

3. Mazala DA, Novak JS, Hogarth MW, Nearing M, Adusumalli P, Tully CB, et al. TGFbeta-driven muscle degeneration and failed regeneration underlie disease onset in a DMD mouse model. JCl Insight. 2020;5(6).

4. Sicinski P, Geng Y, Ryder-Cook AS, Barnard EA, Darlison MG, Barnard PJ. The molecular basis of muscular dystrophy in the $\mathrm{mdx}$ mouse: a point mutation. Science. 1989;244(4912):1578-80.

5. Bulfield G, Siller WG, Wight PA, Moore KJ. X chromosome-linked muscular dystrophy $(\mathrm{mdx})$ in the mouse. Proc Natl Acad Sci USA. 1984;81(4):1189-92.

6. Bobet J, Mooney RF, Gordon T. Force and stiffness of old dystrophic ( $\mathrm{mdx}$ ) mouse skeletal muscles. Muscle Nerve. 1998;21:536-9.

7. Anderson JE, Ovalle WK, Bressler BH. Electron microscopic and autoradiographic characterization of hindlimb muscle regeneration in the $\mathrm{mdx}$ mouse. Anat Rec. 1987;219(3):243-57.

8. Coulton GR, Morgan JE, Partridge TA, Sloper JC. The mdx mouse skeletal muscle myopathy: I. A histological, morphometric and biochemical investigation. Neuropathol Appl Neurobiol. 1988;14(1):53-70.

9. DiMario JX, Uzman A, Strohman RC. Fiber regeneration is not persistent in dystrophic (MDX) mouse skeletal muscle. Dev Biol. 1991;148(1):314-21.

10. Chamberlain JS, Metzger J, Reyes M, Townsend D, Faulkner JA. Dystrophin-deficient $\mathrm{mdx}$ mice display a reduced life span and are susceptible to spontaneous rhabdomyosarcoma. Faseb j. 2007;21(9):2195-204.

11. Massopust RT, Lee YI, Pritchard AL, Nguyen VM, McCreedy DA, Thompson WJ. Lifetime analysis of $\mathrm{mdx}$ skeletal muscle reveals a progressive pathology that leads to myofiber loss. Sci Rep. 2020;10(1):17248.

12. Im WB, Phelps SF, Copen EH, Adams EG, Slightom JL, Chamberlain JS. Differential expression of dystrophin isoforms in strains of $\mathrm{mdx}$ mice with different mutations. Hum Mol Genet. 1996;5(8):1149-53.

379 13. Cullen MJ, Jaros E. Ultrastructure of the skeletal muscle in the $\mathrm{X}$ chromosome-linked 380 dystrophic (mdx) mouse. Comparison with Duchenne muscular dystrophy. Acta Neuropathol. 1988;77(1):69-81. 
14. Dangain J, Vrbova G. Muscle development in $\mathrm{mdx}$ mutant mice. Muscle Nerve. 1984;7(9):700-4.

15. Tanabe $\mathrm{Y}$, Esaki $\mathrm{K}$, Nomura T. Skeletal muscle pathology in $\mathrm{X}$ chromosome-linked muscular dystrophy (mdx) mouse. Acta Neuropathol. 1986;69(1-2):91-5.

16. Torres LF, Duchen LW. The mutant mdx: inherited myopathy in the mouse. Morphological studies of nerves, muscles and end-plates. Brain. 1987;110 ( Pt 2):269-99.

17. Pastoret C, Sebille A. Further aspects of muscular dystrophy in $\mathrm{mdx}$ mice. Neuromuscul Disord. 1993;3:471-5.

18. Lefaucheur JP, Pastoret C, Sebille A. Phenotype of dystrophinopathy in old $\mathrm{mdx}$ mice. Anat Rec. 1995;242:70-6.

19. Pastoret $\mathrm{C}$, Sebille A. mdx mice show progressive weakness and muscle deterioration with age. J Neurol Sci. 1995;129:97-105.

20. Chapman VM, Miller DR, Armstrong D, Caskey CT. Recovery of induced mutations for X chromosome-linked muscular dystrophy in mice. Proc Natl Acad Sci USA. 1989;86(4):12926.

21. Theret M, Gsaier L, Schaffer B, Juban G, Ben Larbi S, Weiss-Gayet M, et al. AMPKalpha1-LDH pathway regulates muscle stem cell self-renewal by controlling metabolic homeostasis. Embo J . 2017;36(13):1946-62.

22. Juban G, Saclier M, Yacoub-Youssef H, Kernou A, Arnold L, Boisson C, et al. AMPK Activation Regulates LTBP4-Dependent TGF-beta1 Secretion by Pro-inflammatory Macrophages and Controls Fibrosis in Duchenne Muscular Dystrophy. Cell Rep. 2018;25(8):2163-76.e6.

23. Desgeorges $\mathrm{T}$, Liot $\mathrm{S}$, Lyon $\mathrm{S}$, Bouvière J, Kemmel A, Trignol A, et al. Open-CSAM, a new tool for semi-automated analysis of myofiber cross-sectional area in regenerating adult skeletal muscle. Skeletal muscle. 2019;9(1):2.

24. Pastoret $\mathrm{C}$, Sebille A. Age-related differences in regeneration of dystrophic $(\mathrm{mdx})$ and normal muscle in the mouse. Muscle Nerve. 1995;18(10):1147-54.

25. Head SI, Williams DA, Stephenson DG. Abnormalities in structure and function of limb skeletal muscle fibres of dystrophic mdx mice. Proc Biol Sci. 1992;248(1322):163-9.

26. Mouisel E, Vignaud A, Hourde C, Butler-Browne G, Ferry A. Muscle weakness and atrophy are associated with decreased regenerative capacity and changes in mTOR signaling in skeletal muscles of venerable (18-24-month-old) dystrophic mdx mice. Muscle Nerve. 2010;41(6):809-18.

27. Louboutin JP, Fichter-Gagnepain V, Thaon E, Fardeau M. Morphometric analysis of mdx diaphragm muscle fibres. Comparison with hindlimb muscles. Neuromuscul Disord. 1993;3(5-6):463-9. 
28. Tamaki T, Sekine T, Akatsuka A, Uchiyama S, Nakano S. Three-dimensional cytoarchitecture of complex branched fibers in soleus muscle from mdx mutant mice. Anat Rec. 1993;237(3):338-44.

29. Chan S, Head SI, Morley JW. Branched fibers in dystrophic mdx muscle are associated with a loss of force following lengthening contractions. Am J Physiol. 2007;293:C985-C92. 30. Head SI. Branched fibres in old dystrophic $\mathrm{mdx}$ muscle are associated with mechanical weakening of the sarcolemma, abnormal $\mathrm{Ca} 2+$ transients and a breakdown of $\mathrm{Ca} 2+$ homeostasis during fatigue. Exp Physiol. 2010;95(5):641-56.

31. Lovering RM, Michaelson L, Ward CW. Malformed mdx myofibers have normal cytoskeletal architecture yet altered EC coupling and stress-induced $\mathrm{Ca} 2+$ signaling. Am J Physiol Cell Physiol. 2009;297(3):C571-80.

32. Pichavant C, Pavlath GK. Incidence and severity of myofiber branching with regeneration and aging. Skeletal muscle. 2014;4:9.

33. Boldrin L, Zammit PS, Morgan JE. Satellite cells from dystrophic muscle retain regenerative capacity. Stem Cell Res. 2015;14(1):20-9.

34. Jiang C, Wen Y, Kuroda K, Hannon K, Rudnicki MA, Kuang S. Notch signaling deficiency underlies age-dependent depletion of satellite cells in muscular dystrophy. Dis Model Mech. 2014;7(8):997-1004.

35. Latroche C, Weiss-Gayet M, Muller L, Gitiaux C, Leblanc P, Liot S, et al. Coupling between Myogenesis and Angiogenesis during Skeletal Muscle Regeneration Is Stimulated by Restorative Macrophages. Stem cell reports. 2017;9(6):2018-33.

36. Latroche C, Matot B, Martins-Bach A, Briand D, Chazaud B, Wary C, et al. Structural and Functional Alterations of Skeletal Muscle Microvasculature in Dystrophin-Deficient mdx Mice. Am J Pathol. 2015;185:2482-94.

37. Ikeda T, Ichii O, Otsuka-Kanazawa S, Nakamura T, Elewa YH, Kon Y. Degenerative and regenerative features of myofibers differ among skeletal muscles in a murine model of muscular dystrophy. J Muscle Res Cell Motil. 2016;37(4-5):153-64.

38. Porter JD, Khanna S, Kaminski HJ, Rao JS, Merriam AP, Richmonds CR, et al. A chronic inflammatory response dominates the skeletal muscle molecular signature in dystrophin-deficient mdx mice. Hum Mol Genet. 2002;11:263-72. 39. Mojumdar K, Liang F, Giordano C, Lemaire C, Danialou G, Okazaki T, et al. Inflammatory monocytes promote progression of Duchenne muscular dystrophy and can be therapeutically targeted via CCR2. EMBO Mol Med. 2014;6:1476-92. improvement of muscular dystrophy in mdx5cv mice. Faseb J. 2017;31(1):35-46. 
41. Arecco N, Clarke CJ, Jones FK, Simpson DM, Mason D, Beynon RJ, et al. Elastase levels and activity are increased in dystrophic muscle and impair myoblast cell survival, proliferation and differentiation. Sci Rep. 2016;6:24708.

42. Straub V, Rafael JA, Chamberlain JS, Campbell KP. Animal Models for Muscular Dystrophy Show Different Patterns of Sarcolemmal Disruption. Journal of Cell Biology. 1997;139(2):375-85.

43. Grounds MD, Terrill JR, Al-Mshhdani BA, Duong MN, Radley-Crabb HG, Arthur PG. Biomarkers for Duchenne muscular dystrophy: myonecrosis, inflammation and oxidative stress. Dis Model Mech. 2020;13(2).

44. Hodgetts S, Radley H, Davies M, Grounds MD. Reduced necrosis of dystrophic muscle by depletion of host neutrophils, or blocking TNFalpha function with Etanercept in mdx mice. Neuromuscul Disord. 2006;16(9-10):591-602.

45. Coulton GR, Curtin NA, Morgan JE, Partridge TA. The mdx mouse skeletal muscle myopathy: II. Contractile properties. Neuropathol Appl Neurobiol. 1988;14(4):299-314.

46. Desguerre I, Mayer M, Leturcq F, Barbet JP, Gherardi RK, Christov C. Endomysial Fibrosis in Duchenne Muscular Dystrophy: A Marker of Poor Outcome Associated With Macrophage Alternative Activation. J Neuropathol Exp Neurol. 2009;68:762-73.

47. Stedman HH, Sweeney HL, Shrager JB, Maguire HC, Panettieri RA, Petrof B, et al. The mdx mouse diaphragm reproduces the degenerative changes of Duchenne muscular dystrophy. Nature. 1991;352:536-9.

48. Goldspink G, Fernandes K, Williams PE, Wells DJ. Age-related changes in collagen gene expression in the muscles of $\mathrm{mdx}$ dystrophic and normal mice. Neuromuscul Disord. 1994;4:183-91.

49. Duclos F, Straub V, Moore SA, Venzke DP, Hrstka RF, Crosbie RH, et al. Progressive muscular dystrophy in alpha-sarcoglycan-deficient mice. The Journal of cell biology. 1998;142(6):1461-71.

50. Fukada S, Morikawa D, Yamamoto Y, Yoshida T, Sumie N, Yamaguchi M, et al. Genetic background affects properties of satellite cells and mdx phenotypes. Am J Pathol. 2010;176(5):2414-24.

51. Coley WD, Bogdanik L, Vila MC, Yu Q, Van Der Meulen JH, Rayavarapu S, et al. Effect of genetic background on the dystrophic phenotype in $\mathrm{mdx}$ mice. Hum Mol Genet. 2016;25(1):130-45.

52. van Putten M, Putker K, Overzier M, Adamzek WA, Pasteuning-Vuhman S, Plomp JJ, et al. Natural disease history of the D2-mdx mouse model for Duchenne muscular dystrophy. Faseb J. 2019:fj201802488R. 
A

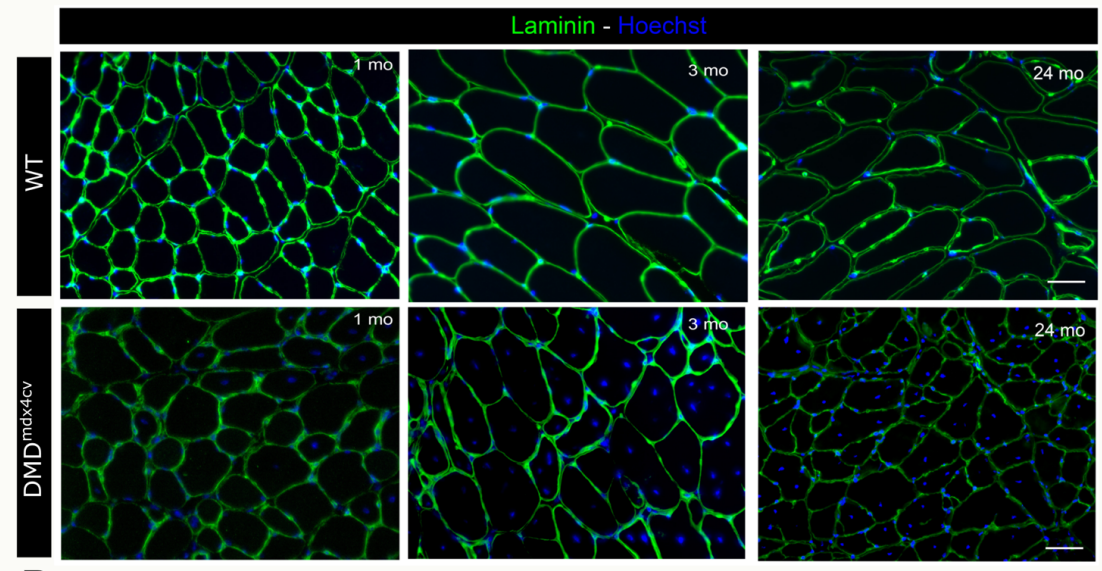

B $p<0.001$

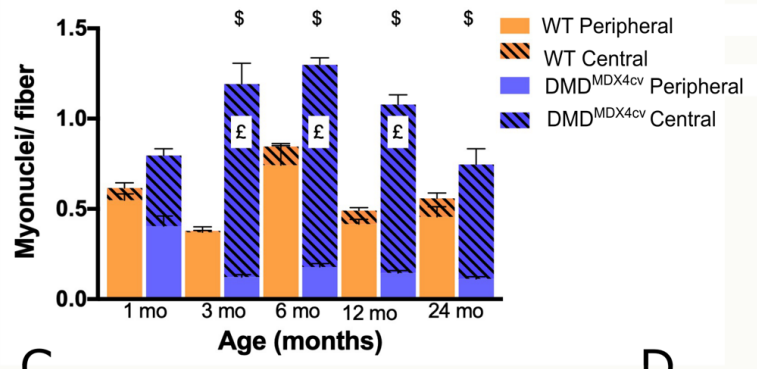

C
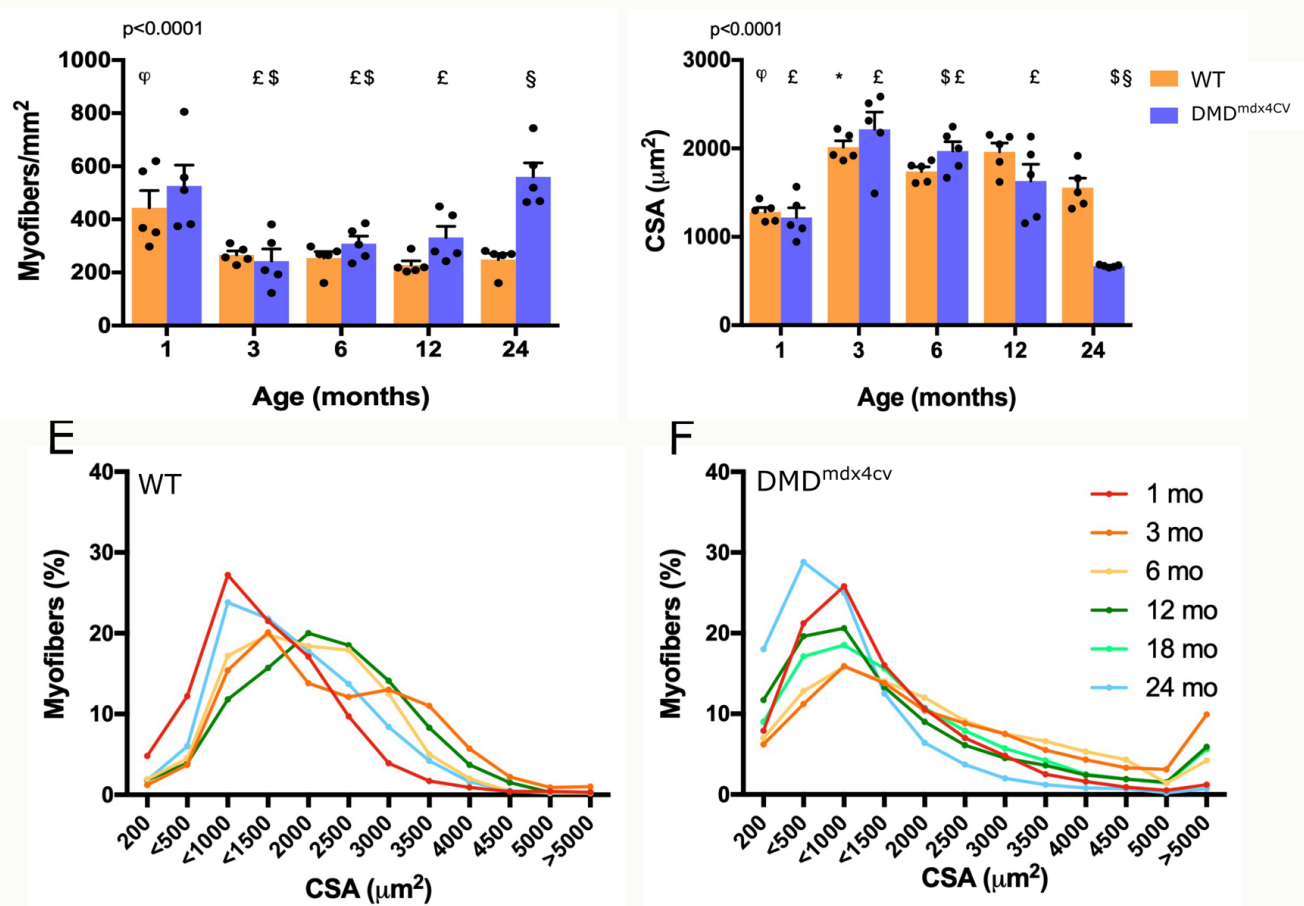

Figure 1. Analysis of myofibers in WT and $\mathrm{DMD}^{m d \times 4 \mathrm{Cv}}$ muscle. TA muscle sections from 1to 24-month-old WT and DMD ${ }^{m d \times 4 C v}$ were immunolabelled for laminin (green) and stained with Hoechst (nuclei) (A). From this immunolabeling, the number and location of nuclei within myofibers (B), the number of myofibers per $\mathrm{mm}^{2}(\mathbf{C})$, mean CSA (D), and CSA distribution (E- 
F) were evaluated. Values are given in means \pm SEM of 5 experiments (one black circle represents one mouse). $\mathrm{P}$ value of Anova analysis is provided on the upper left corner of the graph. Post-hoc comparisons show significant differences. In B, \$ vs $m d x 1$ mo for both central and peripheral myonuclei, $£ v s m d x 24$ mo for central myonuclei only. In $\mathbf{B}$, the number of myonuclei in both central and peripheral positions differs in WT vs $m d x$ for all ages except peripheral myonuclei at $1 \mathrm{mo}$. In $\mathbf{C , D},{ }^{*}$ vs WT $1 \mathrm{mo}, \varphi$ vs WT $12 \mathrm{mo}, \$$ vs $m d x 1 \mathrm{mo}, £$ vs $m d x$ $24 \mathrm{mo}, \S m d x$ vs WT at same age. Bar $=50 \mu \mathrm{m}$. 

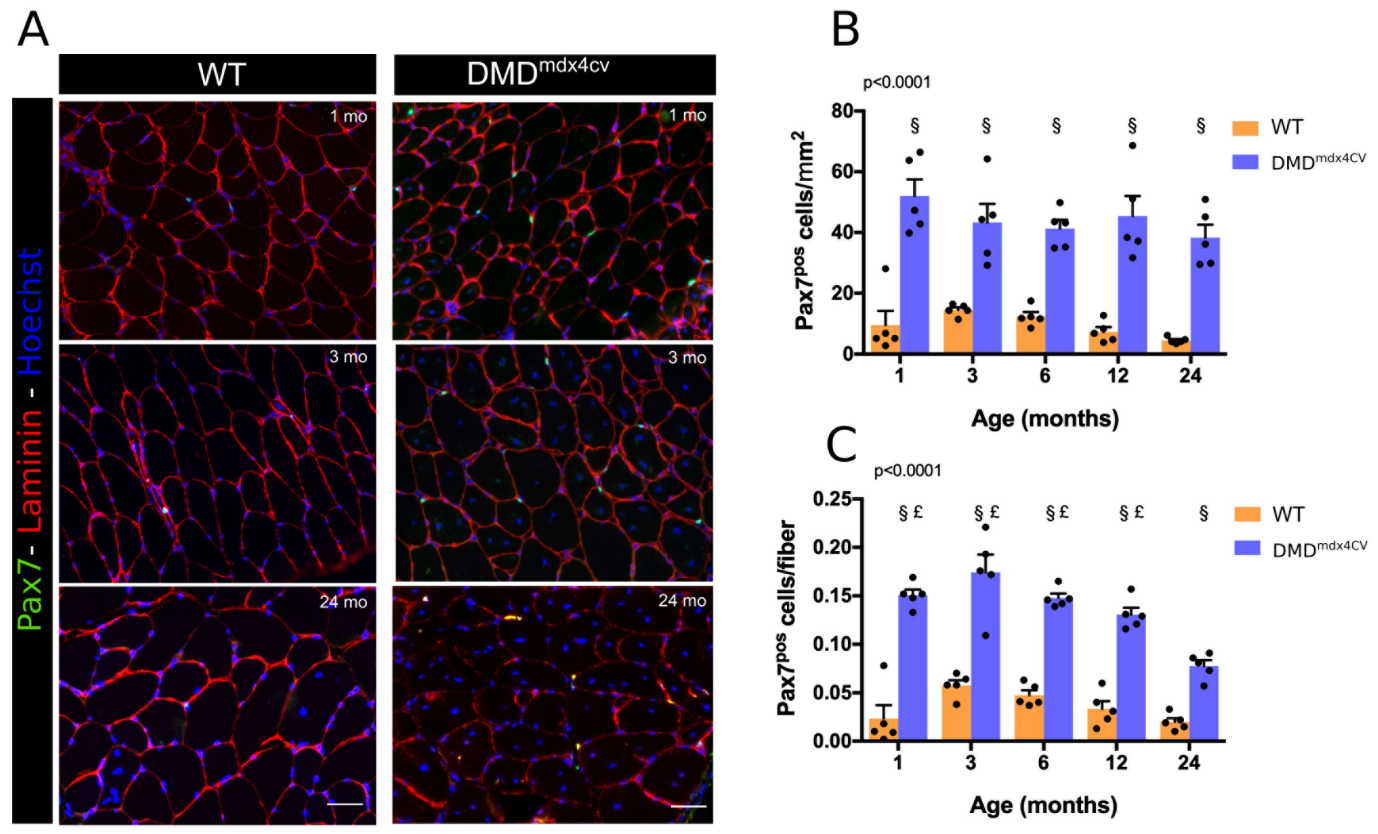

Figure 2. Analysis of satellite cells in WT and DMD ${ }^{m d x 4 C v}$ muscle. TA muscle sections from 1- to 24-month-old WT and DMD ${ }^{m \times 4 C v}$ were immunolabelled for Pax7 (green) and for laminin (red) and stained with Hoechst (nuclei) (A). From this immunolabeling, the number of Pax $7^{\text {pos }}$ cells $/ \mathrm{mm}^{2}(\mathbf{B})$ and the number of Pax $7^{\text {pos }}$ cells/myofiber $(\mathbf{C})$ were evaluated. Values are given in means \pm SEM of 5 experiments (one black circle represents one mouse). $P$ value of Anova analysis is provided on the upper left corner of the graph. Post-hoc comparisons show significant differences for $£ v s m d x 24$ mo and $\S m d x v s W T$ at same age. Bar $=50 \mu \mathrm{m}$. 

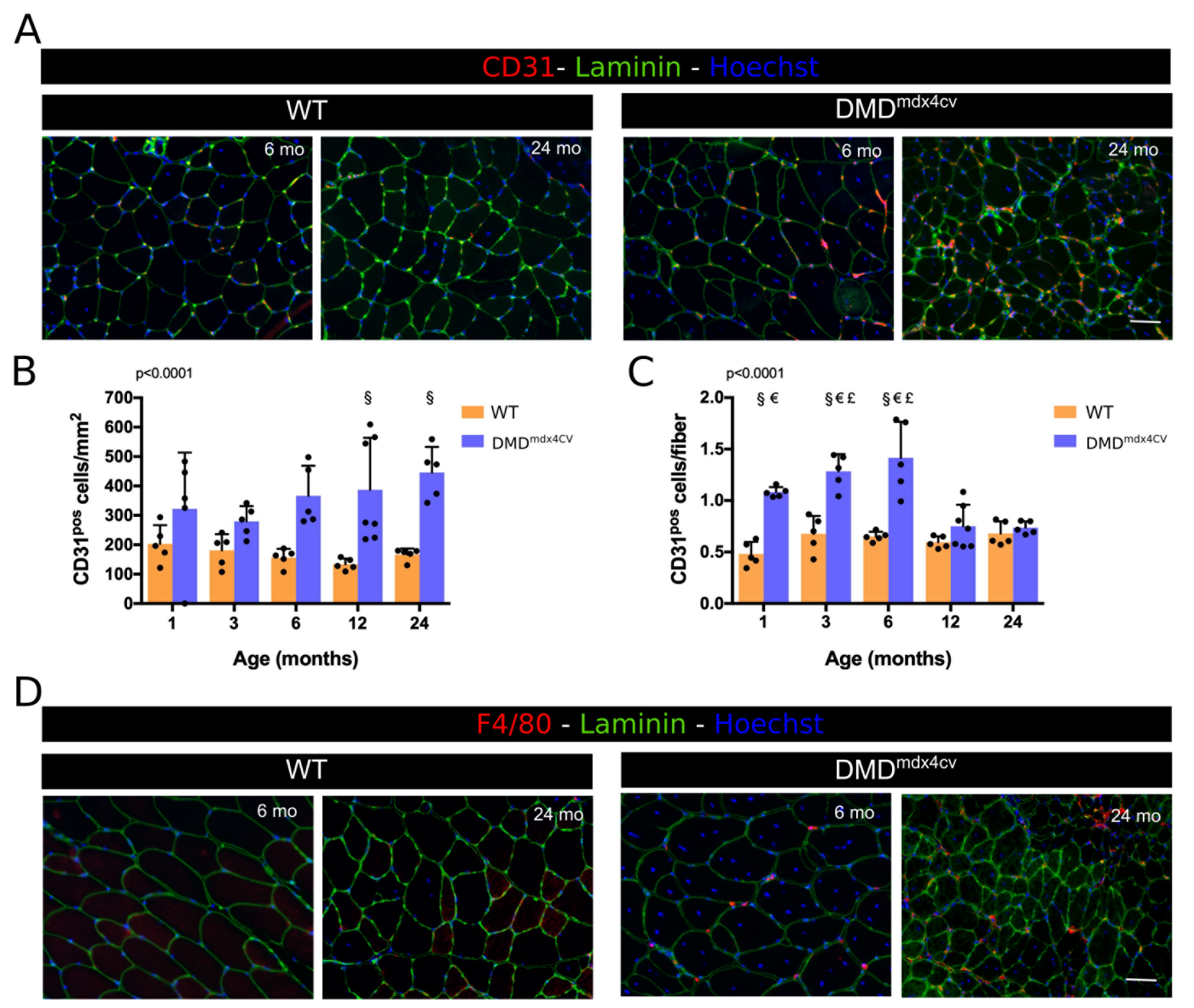

$\mathrm{E}$
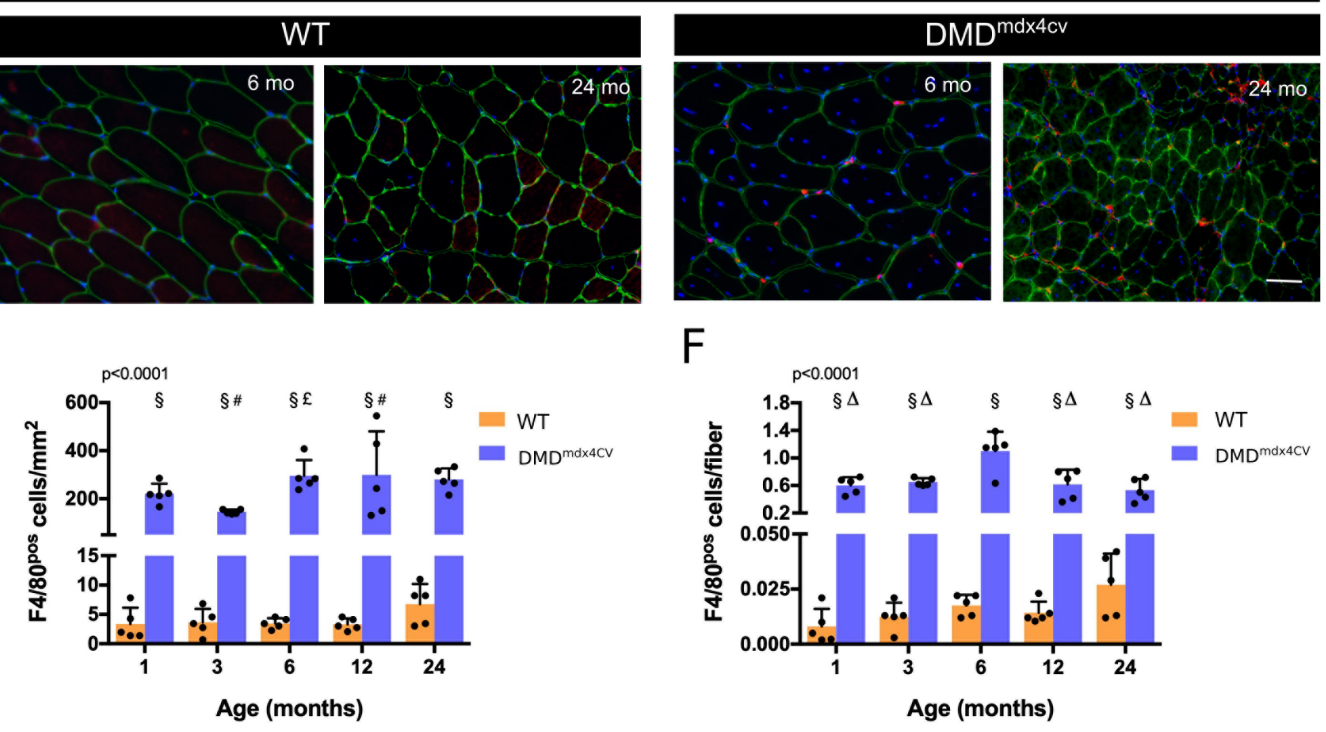

Figure 3. Analysis of endothelial cells and macrophages in WT and DMD ${ }^{m d x 4 C v}$ muscle.

TA muscle sections from 1 to 24-month-old WT and $\mathrm{DMD}^{m d \times 4 C v}$ were immunolabelled for CD31 (red in A) or F4/80 (red in D) and for laminin (green) and stained with Hoechst (nuclei) (A,D). From this immunolabeling, the number of $\mathrm{CD} 31^{\text {pos }}$ cells $/ \mathrm{mm}^{2}(\mathbf{B})$, the number of CD31 ${ }^{\text {pos }}$ cells/ myofiber (C), the number of $\mathrm{F} 4 / 80^{\text {pos }}$ cells $/ \mathrm{mm}^{2}(\mathbf{E})$ and the number of $\mathrm{F} 4 / 80^{\text {pos }}$ cells/myofiber (F) were evaluated. Values are given in means \pm SEM of 5 experiments (one black circle represents one mouse). $\mathrm{P}$ value of Anova analysis is provided on the upper left corner of the graph. Post-hoc comparisons show significant differences for \# vs $m d x 3$ mo, $\Delta$ vs $m d x 6$ mo, $€ v s m d x 12 \mathrm{mo}, £ v s m d x 24 \mathrm{mo}$, and $\S m d x$ vs $\mathrm{WT}$ at same age. Bar $=50 \mu \mathrm{m}$. 
A
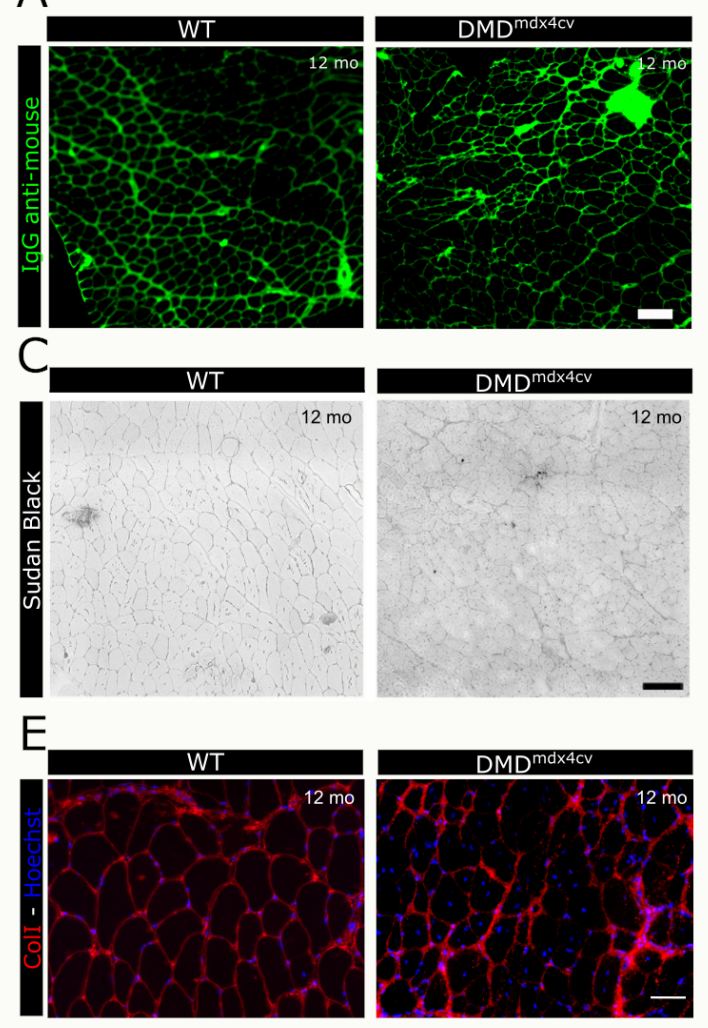
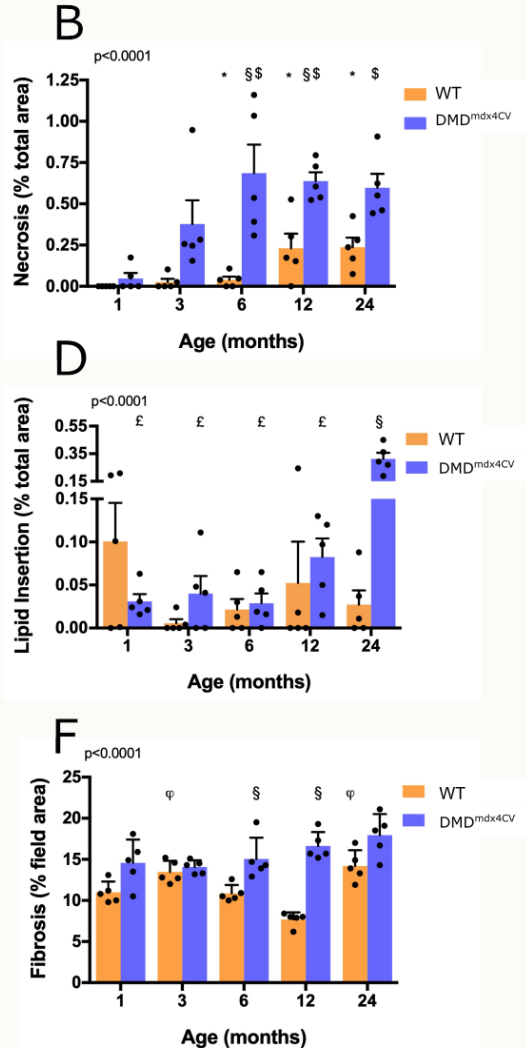

Figure 4. Evaluation of the muscle tissue structure of WT and DMD ${ }^{m d \times 4 C v}$ muscle. Necrosis was evaluated after staining with anti-mouse lgGs (A), as the percentage of total muscle section area (B). Lipid deposition was evaluated after staining with Sudan Black (C), as the percentage of total muscle section area (D). Fibrosis was evaluated after immunolabeling for Collagen I (E), as the percentage of total field area (F). Values are given in means \pm SEM of 5 experiments (one black circle represents one mouse). $P$ value of Anova analysis is provided on the upper left corner of the graph. Post-hoc comparisons show significant differences for * vs WT $1 \mathrm{mo}$, \$ vs mdx $1 \mathrm{mo}, £$ vs $m d x 24 \mathrm{mo}, \varphi$ vs WT 12 mo and $\S m d x$ vs WT at same age. Blue=Hoechst. Bars in $\mathrm{A}, \mathrm{C}=100 \mu \mathrm{m}$, in $\mathrm{E}=50 \mu \mathrm{m}$. 

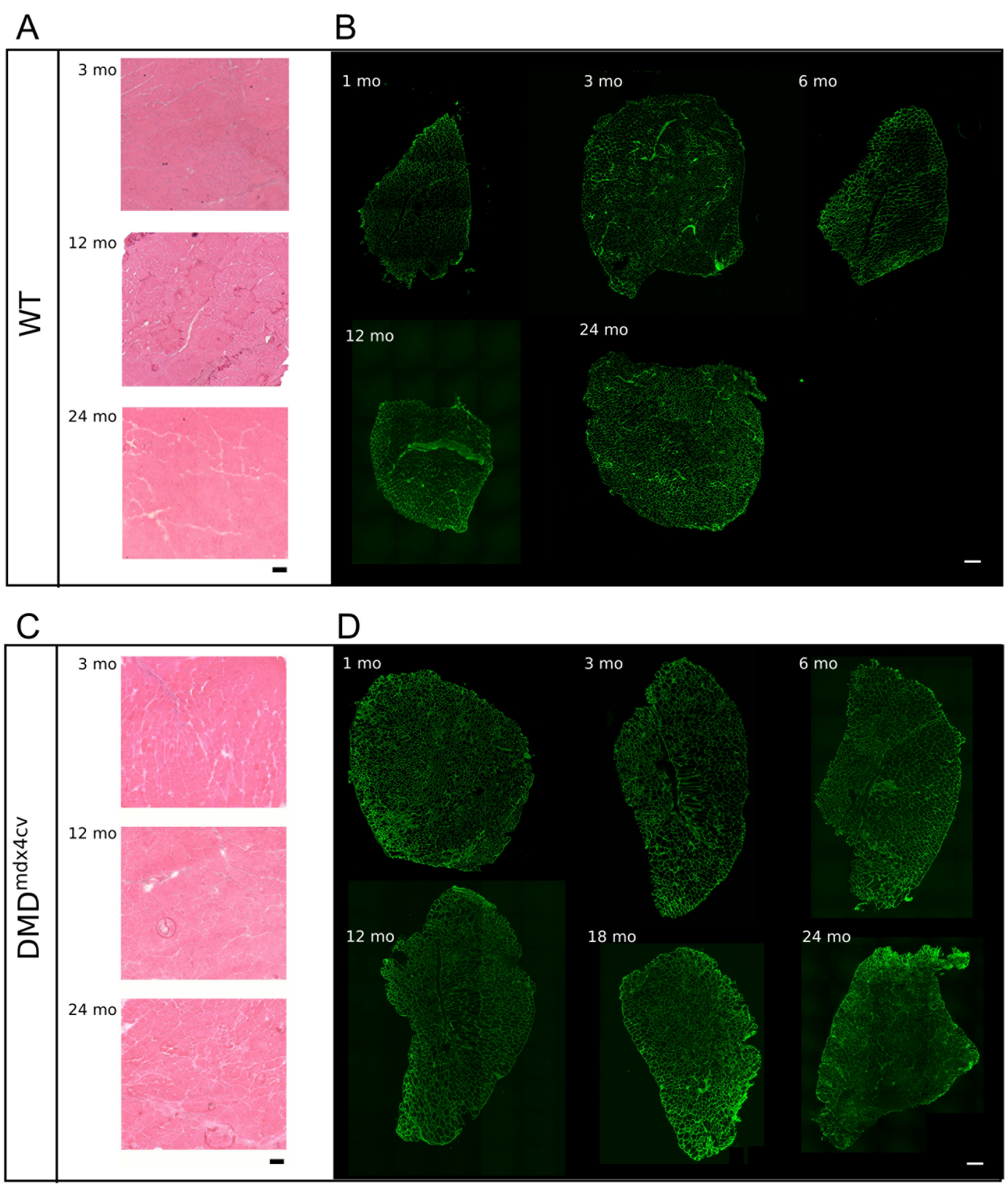

Figure Suppl1. Histology of WT and DMD ${ }^{m d \times 4 C v}$ muscle. TA muscle sections from 1- to 24month-old WT and DMD ${ }^{m d \times 4 C v}$ mice were stained for $\mathrm{HE}(\mathbf{A}, \mathbf{C})$ or immunolabelled for laminin (green) (B, D). Examples of large areas of muscle sections are given for various ages. Bars = $200 \mu \mathrm{m}$. 
A
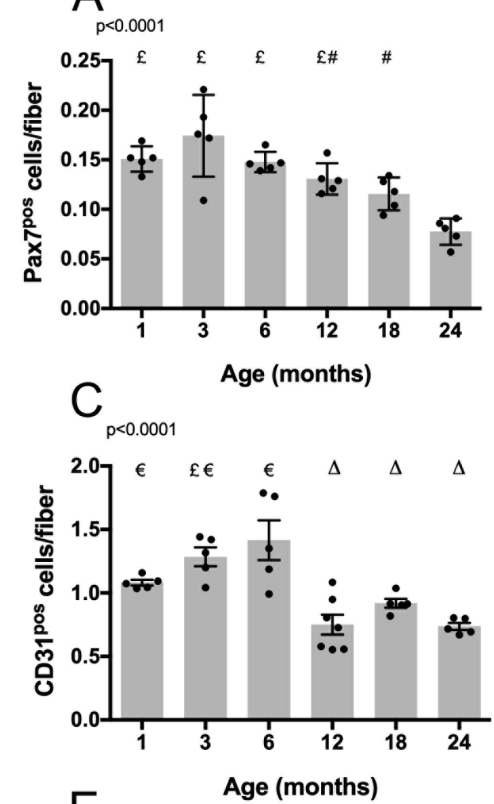

E

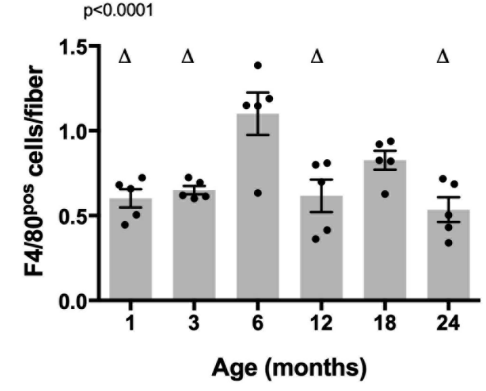

B

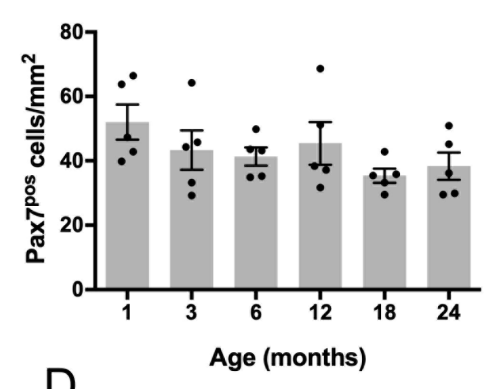

D
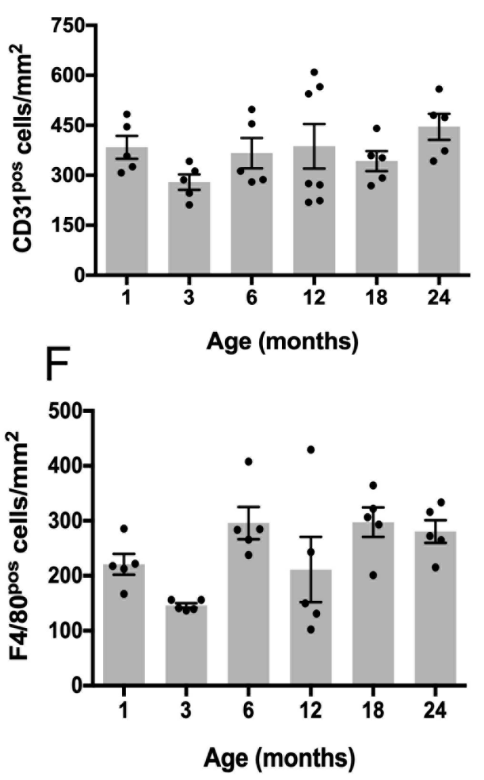

Figure Suppl2. Analysis of satellite cells, endothelial cells and macrophages in $\mathrm{DMD}^{m d \times 4 \mathrm{Cv}}$ muscle. Muscle were treated as described in Figures 2 and 3. P value of Anova analysis is provided on the upper left corner of the graph. Values are given in means \pm SEM of 5 experiments (one black circle represents one mouse). Post-hoc comparisons show significant differences for \# vs $m d x 3 \mathrm{mo}, \Delta$ vs $m d x 6 \mathrm{mo}, € v s m d x 12 \mathrm{mo}, £$ vs $m d x 24 \mathrm{mo}$. 


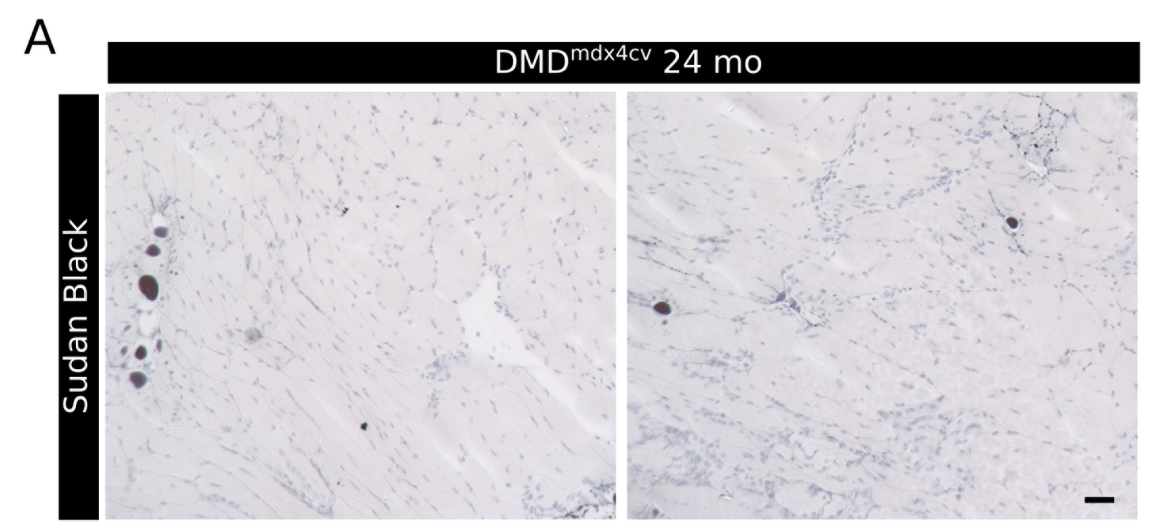

B
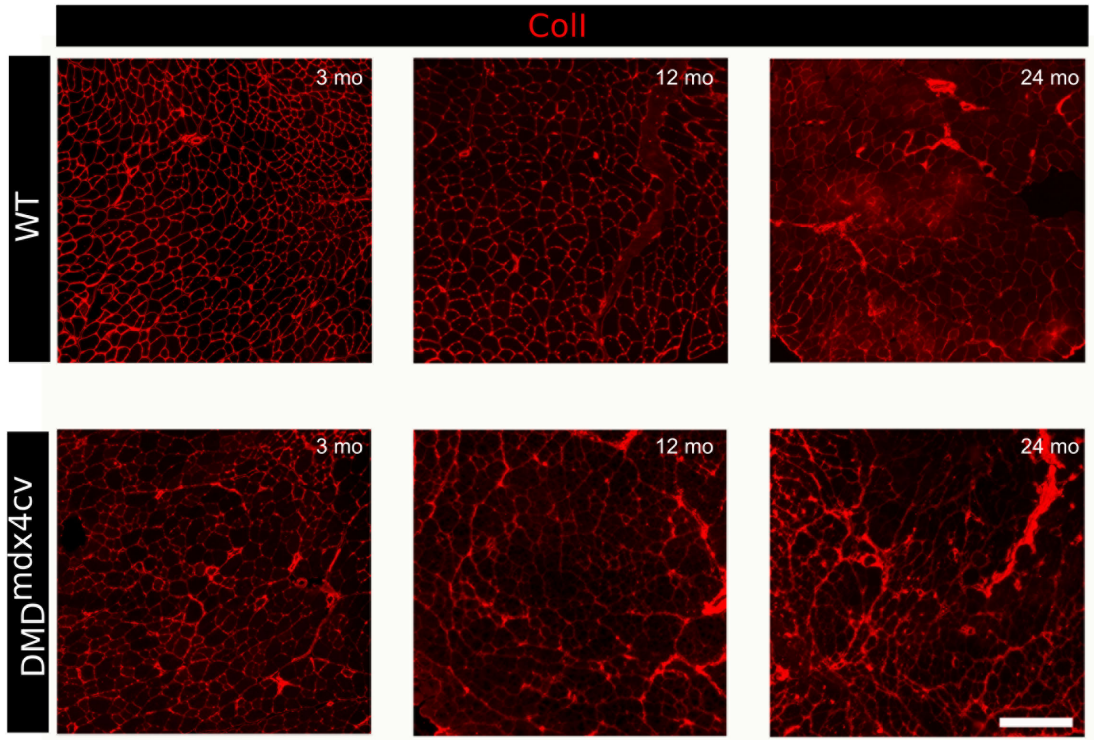

Figure Suppl3. Lipid deposition and fibrosis in WT and $\mathrm{DMD}^{m d \times 4 C v}$ muscle. (A) Example of Sudan Black staining of 24-mo old $\mathrm{DMD}^{m d x 4 \mathrm{Cv}}$ muscle at higher magnification showing rare black lipid droplets. Bar $=50 \mu \mathrm{m}$. (B) TA muscle sections from 3- to 24-month-old were immunolabelled for collagen I. Examples of large areas of muscle sections are given for various ages. Bars $=200 \mu \mathrm{m}$. 